\title{
The Role of Atorvastatin in Management of Eruptive Xanthoma on a Boy: A Case Report
}

\author{
Harapan Parlindungan Ringoringo*(i) \\ Department of Child Health, Faculty of Medicine, Lambung Mangkurat University - RSD Idaman, Banjarbaru, Indonesia
}

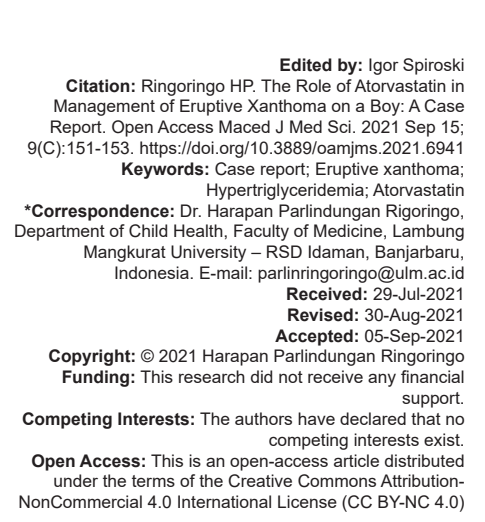

Abstract

BACKGROUND: Eruptive xanthoma (EX) is a benign skin lesion caused by the accumulation of cholesterol and triglycerides in the skin's dermis. Xanthoma can be an early clinical manifestation of systemic diseases such as dyslipidemia, cardiovascular disease, and diabetes mellitus. The clinical presentation varies from asymptomatic skin lesions to intense pruritus and tenderness. This study aims that oral atorvastatin is effective in treating a child with EX.

CASE REPORT: A 3-year-old boy with an $8.4 \mathrm{~kg}$ body weight and $82.5 \mathrm{~cm}$ height came to the hospital with a chief complaint of small yellowish-white papules and nodes, discrete, 2-5 $\mathrm{mm}$ in size, painless on pressing, itchy, scattered, mainly in the lower extremity around the buttocks. On laboratory examination, $\mathrm{Hb} 11.5 \mathrm{~g} / \mathrm{dL}$, leukocyte $9900 / \mathrm{ul}$, platelet $413,000 / \mathrm{uL}$, and blood glucose $66 \mathrm{mg} / \mathrm{dL}$. Further evaluation revealed total cholesterol $814 \mathrm{mg} / \mathrm{dL}$, low-density lipoprotein (LDL) $970 \mathrm{mg} / \mathrm{dL}$, high-density lipoprotein (HDL) $341 \mathrm{mg} / \mathrm{dl}$, triglycerides $621 \mathrm{mg} / \mathrm{dL}$; there is no evidence of familial hypercholesterolemia. The diagnosis is EX. After starting treatment with atorvastatin $0.2 \mathrm{mg} /$ $\mathrm{kg}$ body weight/day in one dose for 6 months, his cutaneous lesions gradually subsided and significantly decreased cholesterol, LDL, HDL, and triglyceride levels.

CONCLUSION: Early therapy with atorvastatin will reduce the morbidity and mortality of EX.

\section{Introduction}

Eruptive xanthoma (EX) is a benign skin lesion caused by the accumulation of cholesterol and triglycerides in the skin's dermis. Xanthoma can be an early clinical manifestation of systemic diseases such as dyslipidemia, cardiovascular disease, and diabetes mellitus. That is why early recognition and therapy of EX can reduce morbidity and mortality [1]. The prominent predilection for EX is in the extremities' extensor skin, back, and buttocks. This disease is characterized by a very high elevation of triglyceride levels. EX prevalence data are not available; however, in patients with severe hypertriglyceridemia, $10 \%$ were accompanied by EX [2]. This case report aims that oral atorvastatin is effective in treating a child with $E X$.

\section{Case Report}

A 3 years and 3-month-old boy with an $8.4 \mathrm{~kg}$ body weight and $82.5 \mathrm{~cm}$ height came to the hospital with a chief complaint of small yellowish-white bumps in the lower leg and around the buttocks, itchy. The patient has no fever, no cough. The patient lacks appetite but often drinks formula milk, moderate malnutrition. In the family, no one has this kind of disease. On physical examination, the patient appears conscious, and vital signs are within the normal limits. Eye, ENT, and mouth had no abnormalities. Heart and lungs within the normal limits. Abdomen: there is no organomegaly. On the skin in the areas: dorsum manus, dorsum pedis, right knee, and left knee, left ankle, right ankle, right elbow, and left elbow, around the buttocks, appear multiple yellowishwhite papules and nodes, discrete, 2-5 $\mathrm{mm}$ in size, painless on pressing, itchy.

On laboratory examination, $\mathrm{Hb} 11.5 \mathrm{~g} / \mathrm{dL}$, leukocyte 9900/ul, platelet 413000/uL, hematocrit 34\%, differential count: basophil $0 \%$, eosinophils $3 \%$, stems $0 \%$, segments $34 \%$, lymphocytes $53 \%$, monocytes $10 \%$. ESR $1 \mathrm{~h} 33 \mathrm{~mm}$, and ESR $2 \mathrm{~h} 52 \mathrm{~mm}$. Blood glucose at $66 \mathrm{mg} / \mathrm{dL}$ (reference range $\leq 115 \mathrm{mg} / \mathrm{dL}$ ), HbA1c $4.2 \%$ (reference range $<7.5 \%$ ). Total cholesterol $-814 \mathrm{mg} / \mathrm{dL}$, low-density lipoprotein (LDL) - 970 mg/dL, high-density lipoprotein(HDL) $-341 \mathrm{mg} / \mathrm{dl}$, and triglycerides $621 \mathrm{mg} / \mathrm{dL}$. Total protein $6.9 \mathrm{~g} / \mathrm{dL}$ (reference range $6-8.2 \mathrm{~g} / \mathrm{dL}$ ), albumin $3.0 \mathrm{~g} / \mathrm{dL}$ (reference range 3.5-5.6 g/dL), and globulin $3.9 \mathrm{~g} / \mathrm{dL}$ (reference range $1.3-2.9 \mathrm{~g} / \mathrm{dL}$ ). Ureum $31 \mathrm{mg} / \mathrm{dL}$ (reference range 15-50 mg/dL), creatinine $0.3 \mathrm{mg} / \mathrm{dL}$ (reference range $\leq 1.4 \mathrm{mg} / \mathrm{dL}$ ), uric acid $3.6 \mathrm{mg} / \mathrm{dL}$ (reference range 3,4-7 $\mathrm{mg} / \mathrm{dL}$ ). Complete urine analysis was within the normal limits. 
Furthermore, laboratory tests on the patient's father showed a triglyceride level of $83 \mathrm{mg} / \mathrm{dL}$, LDL $137.1 \mathrm{mg} / \mathrm{dL}$, and HDL $51.7 \mathrm{mg} / \mathrm{dL}$. The patient's mother's laboratory results showed levels of triglycerides $87 \mathrm{mg} / \mathrm{dL}$, LDL $112 \mathrm{mg} / \mathrm{dL}$, and HDL $41.2 \mathrm{mg} / \mathrm{dL}$.

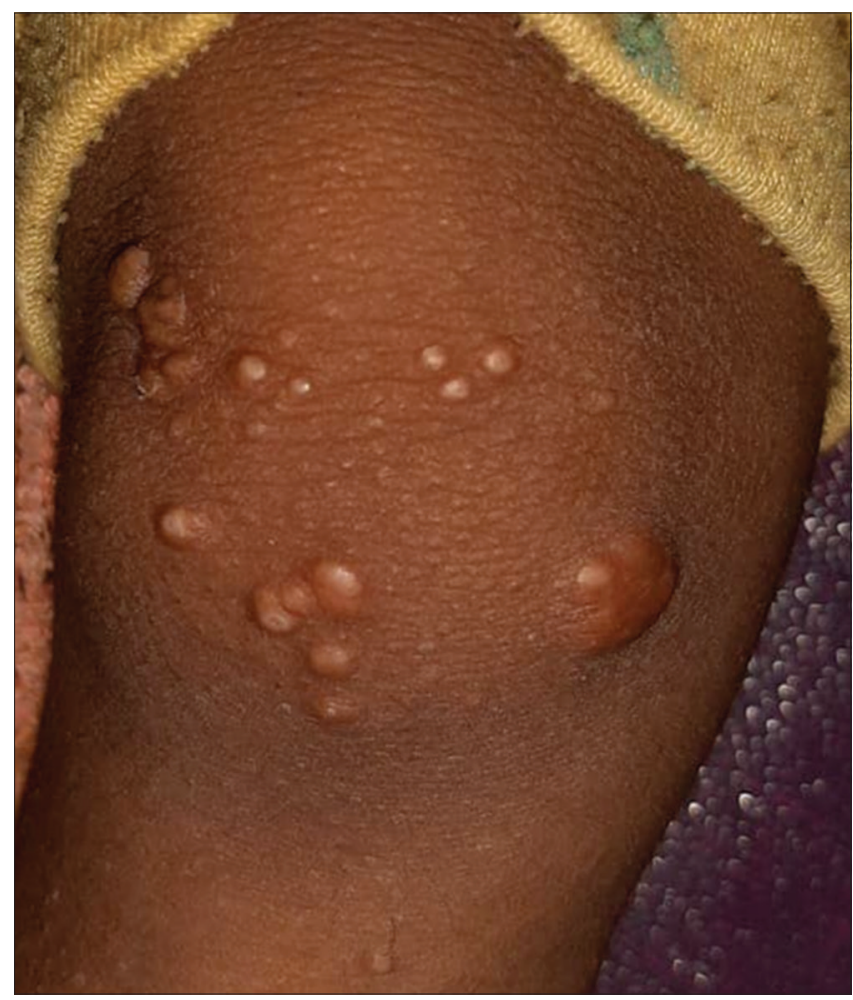

Figure 1: Before treatment of eruptive xanthoma at the knee area

The diagnosis is EX. The therapy was atorvastatin $2 \mathrm{mg} \times 4 \mathrm{mg}$ oral. There was a better clinical change after 4-6 months of treatment (Figures 1 and 2) and a significant decrease in cholesterol, LDL, HDL, and triglyceride levels, as shown in Table 1.

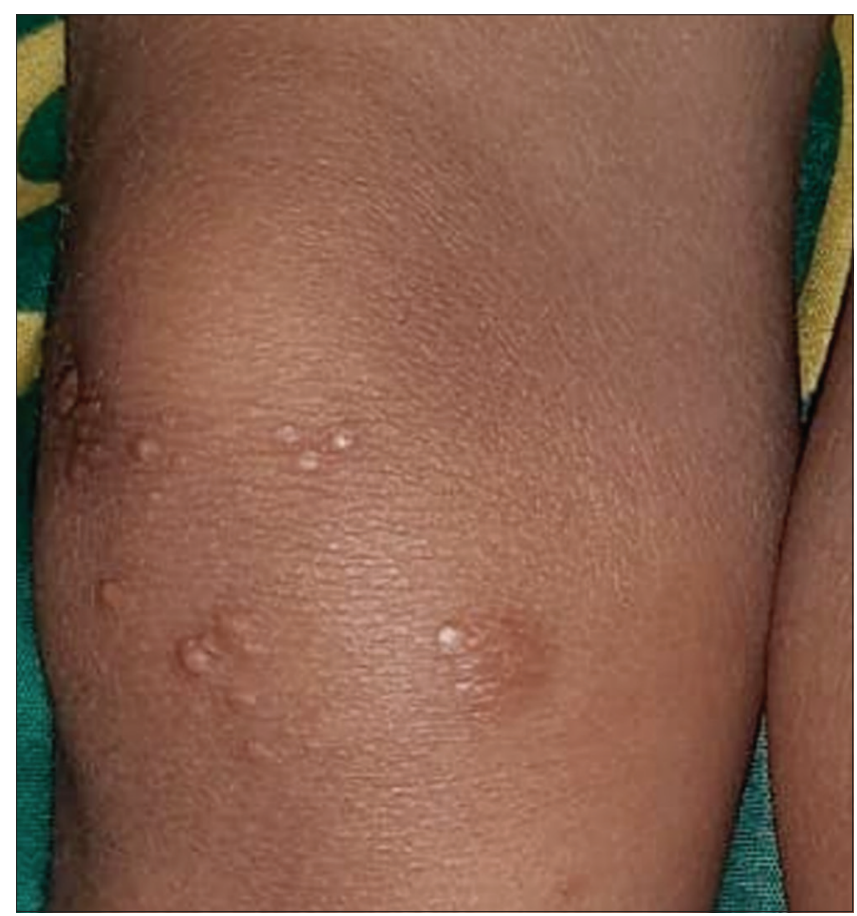

Figure 2: After treatment of eruptive xanthoma at the knee area
Table 1: Blood chemistry parameters of eruptive xanthoma before and after treatment

\begin{tabular}{lllll}
\hline Parameter & $10-03-2020$ & $13-07-2020$ & $31-08-2020$ & Normal range \\
\hline Total Cholesterol $\mathrm{mg} / \mathrm{dL}$ & 814 & 250 & 277 & $130-200$ \\
LDL g/dL & 970 & 192 & 155 & $\leq 150$ \\
$\mathrm{HDL} \mathrm{mg} / \mathrm{dL}$ & 341 & 66 & 105 & $35-55$ \\
Triglycerides mg/dL & 621 & 93 & 151 & $<175$ \\
\hline LDL: Low-density lipoprotein, HDL: High-density lipoprotein. & &
\end{tabular}

\section{Discussion}

Xanthoma patients can be divided into two types, namely [3]: (1). Xanthoma, whose lipid levels are normal, such as xanthoma disseminate (usually very benign), and eosinophilic granuloma syndrome (usually accompanied by chronic disease). (2). Xanthoma accompanied by an increase in lipid levels, such as xanthoma tuberosum (usually accompanied by cardiovascular problems) and EX (often occurs in people with diabetes mellitus). EX in children is a scarce case. Xanthoma can precede clinical symptoms of diabetes mellitus, so we must be vigilant and explore diabetes mellitus [4]. There are several cases of EX accompanied by nephrotic syndrome [5], pancreatitis, hypothyroidism [6]. EX's prominent characteristic appearance is yellowish-white papules, may be accompanied by itching, sizes are usually 1-4 mm, mainly seen on the lower extremities' skin in the extensor area such as the elbows, knees, ankles, buttocks [7]. In this case, there is no evidence of diabetes mellitus, which is characterized by normal glucose levels, negative urine glucose, and $\mathrm{HbA} 1 \mathrm{c}$ levels that are still within normal limits. Urea and creatinine values are within the normal limits indicating that there is no impaired renal function.

In EX, there was an increase in cholesterol levels and high triglycerides. In this case, there is a very high increase in LDL, HDL, and triglycerides. In this case, there is no evidence of familial hypercholesterolemia due to the parent's cholesterol, LDL, HDL, triglyceride levels are within the normal limits. Xanthoma lesions occur due to the uptake and storage of cholesterol, triglycerides, and phospholipids by macrophages with the accumulation in the dermis

In this case, if the WHO weight-for-height boys and the height-for-age boy's growth curve are used, the nutritional status of this child is classified as severe-wasted, stunted. However, this nutritional state is not associated with hypercholestrolemia and hypertriglyceridemia. Maria's research on children under 5 years of age showed that levels of LDL and HDL were lower $(p=0.036)$, and triglycerides were higher (not significant) in the group suffering from acute malnutrition than in the normal group of children [8].

Dyslipidemia in childhood will increase the risk of atherosclerosis and cardiovascular disease in adulthood. The American Academy of Pediatrics recommends that the target LDL level in children is $\leq 130 \mathrm{mg} / \mathrm{dL}$ [9]. The primary treatment, in this case, is a modification of the 
daily diet with low in fat, low in carbohydrates, exercise, and atorvastatin [10]. The primary mechanism of action of statins is inhibition of the enzyme-3-hydroxymethylglutaryl-coenzyme A reductase. This mechanism is a rate limiting step in the biosynthesis of cholesterol. Reduced intrahepatic cholesterol leads to decreased very LDL assembly [11], [12]. Statins have also been proposed to be beneficial to prevent the progression of atherosclerosis by their pleiotropic effect [13]. Statins do not impact growth or development [14]. In this case, oral atorvastatin was given $0.2 \mathrm{mg} / \mathrm{kg}$ body weight/ day in one dose for 6 months. It is proven that after 4-6 months of treatment, the patient's clinical condition is getting better, and the itching is completely gone. It is marked by a significant reduction in cholesterol, LDL, HDL, and triglyceride levels. The 20 years' follow-up studies on the use of statins in pediatric dyslipidemia did not report significant adverse severe events [15].

\section{Conclusion}

EX marks the beginning of serious complications such as dyslipidemia, cardiovascular disease, and diabetes mellitus. Supposed EX is treated early, morbidity and mortality will be reduced.

\section{References}

1. Kashif $\mathrm{M}$, Kumar $\mathrm{H}$, Khaja $\mathrm{M}$. An unusual presentation of eruptive xanthoma: A case report and literature review. Medicine (Baltimore). 2016;95(37):e4866. https://doi.org/10.1097/ md.0000000000004866

PMid:27631252

2. Zak A, Zeman M, Slaby A, Vecka M. Xanthomas: Clinical and pathophysiological relations. Biomed Pap. 2014;158(2):181-8. https://doi.org/10.5507/bp.2014.016

PMid:24781043

3. Crocker AC. Special reviews: Skin xanthomas in childhood. Pediatrics. 1951;8(4):573-97.

PMid:14882914
4. Odeh AA. Xanthoma in a child as the first presentation of type one diabetes mellitus. Pediatr Ther. 2015;5:226.

5. Teltscher J, Silverman RA, Stork J. Eruptive xanthomas in a child with the nephrotic syndrome. J Am Acad Dermatol. 1989;21(5 Pt 2):1147-9. https://doi.org/10.1016/s0190-9622(89)70319-4 PMid:2808850

6. Parker F. Xanthomas and hyperlipidemias. J Am Acad Dermatol. 1985;13(1):1-30.

PMid:4031142

7. Zaremba J, Zaczkiewicz A, Placek W. Eruptive xanthomas. Adv Dermatol Allergol. 2013;6(6):399-402. https://doi.org/10.5114/ pdia.2013.39439

PMid:24494004

8. Maria VR, Maria OC. Dyslipidemia in Children with Acute Malnutrition. Turbo, Colombia. Perspect Nut Hum vol14 no2 Medellín July/Dec 2012; 2012.

9. Expert Panel on Integrated Guidelines for Cardiovascular Health and Risk Reduction in Children and Adolescents; National Heart, Lung, and Blood Institute. Expert panel on integrated guidelines for cardiovascular health and risk reduction in children and adolescents: Summary report. Pediatrics. 2011;128(Suppl 5):S213-56. https://doi.org/10.1542/ peds.2009-2107c

PMid:22084329

10. Nikolic D, Corina A, Toth PP, Hammad L, Rizzo M. Choosing an ideal pharmacotherapeutic strategy for dyslipidemia in children. Expert Opin Pharmacother. 2019;20(3):241-4. https://doi.org/10 $.1080 / 14656566.2018 .1552942$

PMid:30521406

11. Brown MS, Goldstein JL. A receptor-mediated pathway for cholesterol homeostasis. Science. 1986;232(4746):34-47. https://doi.org/10.1126/science.3513311 PMid:3513311

12. Ness GC, Chambers CM, Lopez D. Atorvastatin action involves diminished recovery of hepatic HMG-CoA reductase activity. J Lipid Res. 1998;39(1):75-84. https://doi.org/10.1016/ s0022-2275(20)34205-x PMid:9469588

13. Labos C, Brophy JM, Smith GD, Sniderman AD, Thanassoulis G. Evaluation of the pleiotropic effects of statins. Arterioscler Thromb Vasc Biol. Am Heart Assoc. 2018;38:262-5.

14. Khoury M, McCrindle BW. The rationale, indications, safety, and use of statins in the pediatric population. Can J Cardiol. 2020;36(9):1372-83. https://doi.org/10.1016/j.cjca.2020.03.041 PMid:32735868

15. Luirink IK, Wiegman A, Kusters DM, Hof MH, Groothoff JW, de Groot E, et al. 20-year follow-up of statins in children with familial hypercholesterolemia. N Engl J Med. 2019;381(16):1547-56. https://doi.org/10.1056/nejmoa1816454

PMid:31618540 